\title{
"Dye Industry Effluent Treatment Using Cactus (Opuntia) And Water Hyacinth (Eichhornia Crassipes)"
}

\author{
${ }^{1}$ DR.T.Kannadasan, ${ }^{2}$ M.Thirumarimurugan, ${ }^{3}$ K.S.Sowmya, \\ ${ }^{4}$ Sukanya karuppannan, ${ }^{5} \mathrm{M}$.Vijayashanthi, \\ ${ }^{1}$ head of the department,department of chemical engineering, Coimbatore institute of technology \\ ${ }^{2}$ Associate professor,Department of Chemical Engineering, Coimbatore Institute of Technology. \\ ${ }^{3,4,5}$ Department of Chemical Engineering, Coimbatore Institute of technology.
}

\begin{abstract}
Coagulation is an important wastewater treatment process used to reduce water turbidity and normally precedes the more complex secondary and tertiary water treatment process. In this study, the effectiveness of a natural coagulant derived from a cactus species for turbidity removal from dye industry effluent. Other parameters such as $\mathrm{pH}$ as well as colour were also studied. The amount of cactus added was well correlated with final turbidity of the water. High turbidity removal determined in this study indicates that cactus (opuntia) and water hyacinth (eichhornia crassipes) has the potential to be utilised for waste water treatment applications.
\end{abstract}

Key Words: Cactus,Dye industry effluent,pH, Turbidity, water hyacinth

\section{Introduction:}

Waste water is the major environmental issue of textile industries besides other minor issues like solid waste, resource wastage and occupational,health and safety.Textile and dyeing mills use many kinds of artificial composite dyes and discharge large amount of highly coloured wastewater. Textile waste water pollutants are generally causticsoda, urea, detergents,starch,wax,ammonia pigments and dyes. These wastes must be treated prior to discharge inorder to comply with the environmental protection laws for the receiving waters.Biological treatment processes are frequently used to treat textile effluents.Coagulation is an essential process in the treatment of industrial waste water.Examples of chemical based coagulants that are available commercially include lime,alum,ferric chloride and polyaluminium chloride. While the effectiveness of these chemicals as coagulants are well noted,there are,none the less,disadvantages linked with usage of these coagulants such as comparatively high costs,harmful effects on human health as well as the fact that they appreciably affect $\mathrm{pH}$ of treated waters.As such,it is desirable to substitute these chemical coagulants with cost-effective natural coagulants to offset the aforesaid disadvantages.Cactus (opuntia)and water hyacinth (Eichhornia crassipes)exhibited high turbidity removal efficiency.

\section{Preparation and characterization of cactus powder and water hyacinth:}

Cactus opuntia used in the study was collected from a nursery.The cactus was washed with tap water and subsequently sliced into small pieces to facilitate drying.The sliced cactus was then dried under direct sunlight and then kept in oven for 6 hours at $80^{\circ} \mathrm{C}$.The dried cactus was ground into fine powders using pestle and mortar.

Water hyacinth used in the study was collected from a nearby pond.The roots of hyacinth was washed thoroughly and then dried under direct sunlight .The dried roots was ground into fine powders using pestle and mortar.

\section{Collection and characteristics of water sample:}

The sample was collected from Valli process dyeing factory pvt ltd.It was observed that the samples were turbid and bluish - green in colour. The initial $\mathrm{pH}$ was measured using digital $\mathrm{pH}$ meter and the $\mathrm{pH}$ observed was 9.23.

\section{Magnetic Stirrer Test:}

Magnetic Stirrer test was used to determine the effectiveness of using cactus powder as coagulant.The test was conducted using magnetic stirrer apparatus using $50 \mathrm{ml}$ to $1000 \mathrm{ml}$ beakers.Raw effluent sample of 50 $\mathrm{ml}$ were stirred in the stirrer. Cactus powder of dosages of $0.5,1,1.5,2$ and 2.5 grams were added to the effluent samples.This was the mixing stage.After a period of time coagulation gets started and the samples were allowed to stand for 30 minutes after which treatment was completed(settling stage).Turbidity and $\mathrm{pH}$ of samples before 
and after the test were measured and tabulated.Turbidity values were determined via Nephlometer while $\mathrm{pH}$ values were determined via digital $\mathrm{pH}$ meter .

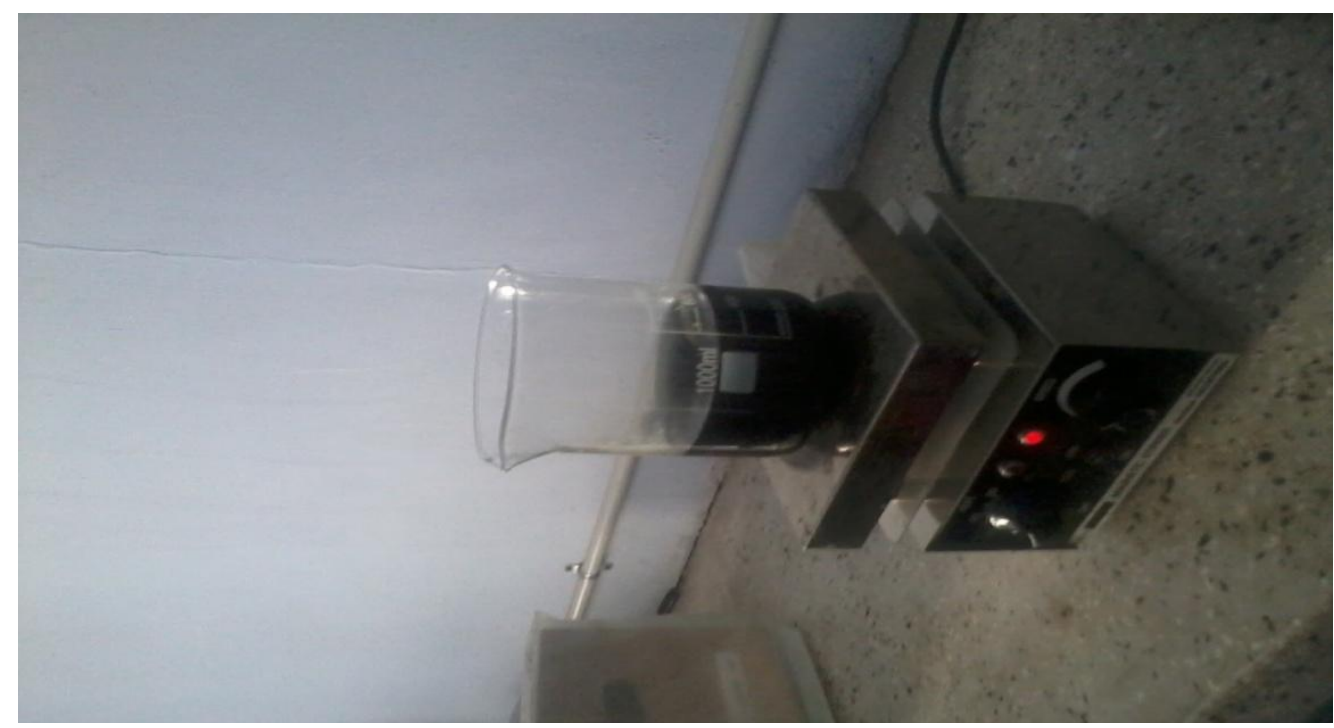

\section{Characterization of cactus opuntia:}

\section{Results and Discussion:}

Elemental analysis was carried out to provide elemental compositions of the cactus .In this study,it was determined that cactus opuntia contained $2.3 \%$ nitrogen, $29.4 \%$ carbon, $1.7 \%$ hydrogen. The coagulant was slightly acidic in presence of water.It was observed that increased cactus dosages correlated with decreased $\mathrm{pH}$.

\section{Effect of cactus and water hyacinthdosage on $\mathrm{pH}$ of the sample:}

Initial $\mathrm{pH}$ of cactus powder mixed in distilled water was 6.5 (slightly acidic). The below graph shows the effect of dosage of cactus powder on $\mathrm{pH}$ of the water. For the graph concentration is taken along abscissa and $\mathrm{pH}$ on the ordinate. It is seen that increased cactus dosages from 0.5 to $2.5 \mathrm{~g}$ had a marginal effect on final $\mathrm{pH}$ of the water ( $\mathrm{pH}$ value 8.2).The same experiment when conducted with water hyacinth resulted in minute changes in $\mathrm{pH}$,which is less compared to cactus. This result implied that even though the dosages were substantially increased, final $\mathrm{pH}$ values of the water were relatively unaffected as compared to usage of chemical- based coagulants.

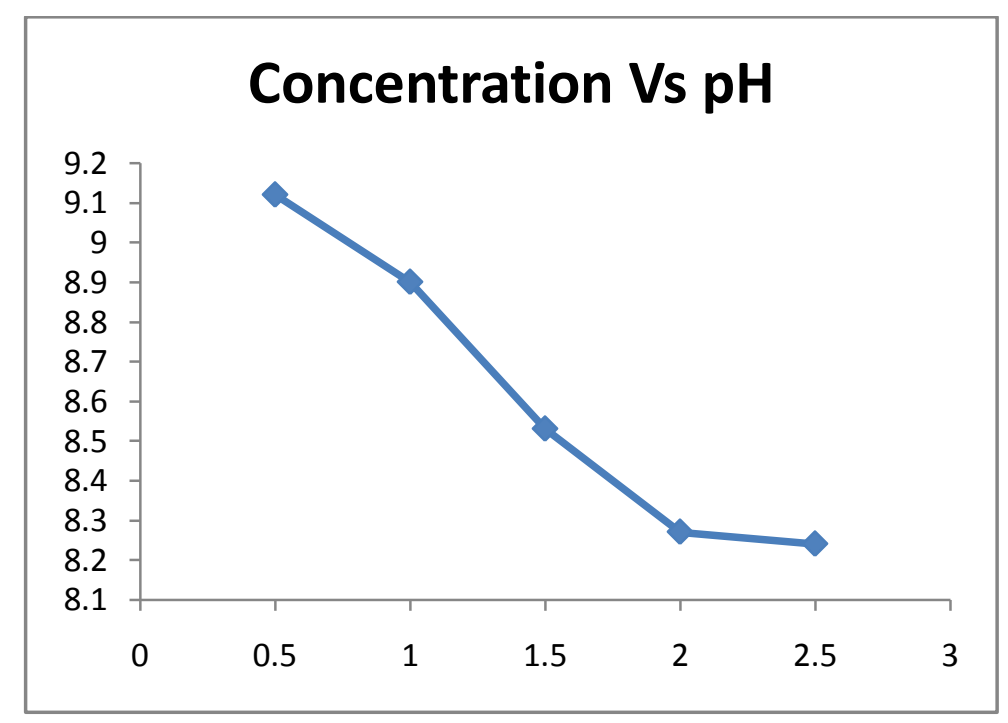

Effect of cactus and water hyacinth dosage on turbidity removal:

It was observed that the powdered cactus formed large flocs with impurities in the sample which facilitated settling and as a result,clear supernatant was produced. Fig shows the effect of dosage of cactus 
powder and water hyacinth on turbidity of the waters. For graph concentration was taken along $\mathrm{x}$-axis and turbidity was taken along y-axis. Initial turbidity values measured were $2250 \mathrm{ppm}$ for the effluent water.Turbidity removal efficiencies after treatment at various dosages range from $80-85 \%$ which is 1845 $\mathrm{ppm}$.The same experiment with water hyacinth resulted in minute changes, which is less compared to cactus.

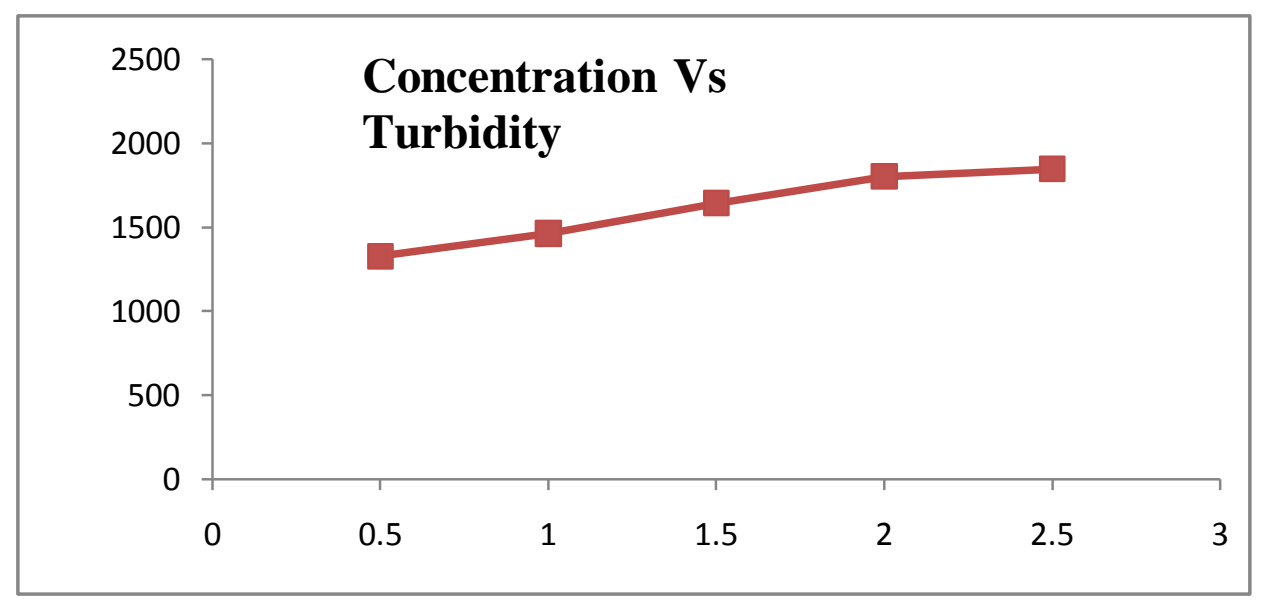

\section{Conclusions:}

It was shown that powdered and dried cactus opuntia was very effective in removing turbidity from effluent water than water hyacinth.It is proven that it has an effect on final $\mathrm{pH}$ of waters as compared to chemical based coagulants.Increased cactus and water hyacinth dosages correlated with decreased $\mathrm{pH}$ of the effluent water.It can be concluded that cactus opuntia and water hyacinth has the potential to be utilized for waste water treatment applications.

\section{Acknowledgments:}

We would like to express our gratitude to our beloved principal,DR.V.SELLADURAI and our Head Of the Department, DR.T.KANNADASAN for their support and encouragement in completing this project. We would not have nurtured our thoughts to complete this project with great success without the guidance of our project guide, Dr.M.THIRUMARIMURUGAN, Associate professor of Chemical Engineering. We are very grateful and thankful to Dr.C.KARUPPANNAN beckoned light on us in our life.

\section{References:}

[1]. Edzwald,J.k. (1993)."Coagulation in drinking water treatment: particles,organics,andcoagulants."Water science technology,27(11),2135 .

[2]. Fatoki,O.S and ogunfowokan,A.O. (2002).Effect of coagulant treatment on the metal composition of raw water." Water SA,28(3),293298.

[3]. Kang,M.,kamei,T. and Magara,y. (2003)."Comparing polyaluminium chloride and ferric chloride for antimony removal."Water research, 37(17),4171-4179.

[4]. Liew , A.G.,Noor,M.J.M.M. and Ng, Y.M. (2004). "Coagulation of turbid waters using extraction of long bean.”Malaysian journal of science, 23,185-191.

[5]. Ndabigengesere, A.,Narasiah,K.S. and Talbot,B.G. (1995)."Active agents and mechanisms of coagulation of turbid waters using moringaolifera." Water research ,29(2),703-710.

[6]. Ndabigengesere,A. and Narasiah. K.S.(1998)."Quality of water treated by coagulation using moringaolifera seeds" water research,32(3)781-791.

[7]. Muyibi,S.A. and Evison,L.M.(1995)."Optimizing physical parameters affecting coagulation of turbid water with moringaolifera seeds." Water research,29(12),2689-2695. 